\title{
Information structuring improves recall of emergency discharge information: a randomized clinical trial
}

\author{
Selina Ackermann ${ }^{\mathrm{a}, \mathrm{b}}$, Leyla Ghanim ${ }^{\mathrm{b}}$, Anette Heierle ${ }^{\mathrm{b}}$, Ralph Hertwig ${ }^{\mathrm{c}}$, Wolf Langewitz ${ }^{\mathrm{d}}$, \\ Rui Mata ${ }^{\mathrm{a}}$ and Roland Bingisser ${ }^{\mathrm{b}}$ \\ ${ }^{a}$ Department of Psychology, University of Basel, Basel, Switzerland; bepartment of Emergency Medicine, \\ University Hospital Basel, Basel, Switzerland; ' $C e n t e r$ for Adaptive Rationality, Max Planck Institute for Human \\ Development, Berlin, Germany; 'Department of Psychosomatic Medicine, University Hospital Basel, Basel, \\ Switzerland
}

\begin{abstract}
This article examines the extent to which structuring Emergency Department discharge information improves the ability to recall that information, and whether such benefits interact with relevant prior knowledge. Using three samples of students with different levels of prior medical knowledge, we investigated the amount of information recalled after structured vs. non-structured presentation of information. Across all student samples, the structured discharge information led to a relative increase in recalled items of $17 \%$ compared to non-structured discharge information $(M=9.70$, $\mathrm{SD}=4.96$ vs. $M=8.31, \mathrm{SD}=4.93$ ). In the sample with least medical knowledge, however, the structured discharge information resulted in a relative increase in recall by $42 \%(M=8.12 \mathrm{vs} . M=5.71)$. These results suggest that structuring discharge information can be a useful tool to improve recall of information and is likely to be most beneficial for patient populations with lower levels of medical knowledge.
\end{abstract}

\section{ARTICLE HISTORY}

Received 4 December 2015

Accepted 1 June 2016

\section{KEYWORDS}

Emergency department; discharge communication; physician-patient communication; recall; information structuring

\section{Introduction}

\section{The importance of discharge information}

Communication between physician and patient represents a fundamental element of health care (Ong, de Haes, Hoos, \& Lammes, 1995). Efficient physician-patient communication in the context of the Emergency Department (ED) may be particularly challenging. According to the Society for Academic Emergency Medicine's Task Force on PhysicianPatient Communication (Knopp, Rosenzweig, Bernstein, \& Totten, 1996), numerous features of the ED environment render effective physician-patient communication difficult, including time pressure and high stress levels. Discharge from the ED is a period of high vulnerability (Samuels-Kalow, Stack, \& Porter, 2012). Inappropriate communication at discharge may result in patients leaving the ED with too little knowledge to optimally monitor their health status at home (Crane, 1997; Engel et al., 2009, 2012; Jolly, Scott, \& Sanford, 1995; Logan, Schwab, Salomone, \& Watson, 1996; Spandorfer, Karras, Hughes, \& Caputo, 
1995). In addition, it can increase the likelihood of adverse events, often related to incorrect adherence to medication, to repeat ED visits, and lack of follow-up on pending test results (Bazarian, Hartman, \& Delahunta, 2000; Butler \& Cooper, 2004; Clarke et al., 2005; Engel et al., 2009; Foran, Wuerth-Sarvis, \& Milne, 2010; Grover, Berkowitz, \& Lewis, 1994; Han, Barnard, \& Chapman, 2009; Hastings et al., 2011; Lerman \& Kobernick, 1987). Systematic literature reviews suggest a number of interventions to improve discharge communication (Samuels-Kalow et al., 2012; Watson \& McKinstry, 2009), such as using graphic aids (Houts et al., 1998; Wolf et al., 2011; Zeng-Treitler, Kim, \& Hunter, 2008), checking for comprehension (Fink et al., 2010; Schillinger et al., 2003; White, Mason, Feehan, \& Templeton, 1995), assistance with follow-up appointments (Racine, Alderman, \& Avner, 2009; Vinson \& Patel, 2009; Zorc, Chew, Allen, \& Shaw, 2009), standardizing the information (Considine \& Brennan, 2007; Graumlich, Novotny, Nace, \& Aldag, 2009; Isaacman, Purvis, Gyuro, Anderson, \& Smith, 1992; Rogers et al., 2007), as well as combined approaches such as the PODS tool (Hahn-Goldberg et al., 2016). One way to standardize communication is to provide written information (Johnson \& Sandford, 2005); however, this can be difficult and time-consuming, in particular if information is not to be generic but tailored to the needs of a specific patient, and if patient literacy is low, or the diagnosis is (yet) unclear. One alternative therefore is to ensure that oral communication follows certain structural characteristics that boost its future retrieval.

\section{Recall of medical information}

Communication during an ED encounter will only have a beneficial impact on the patient's health if the essential content is conveyed such that the chances of its recall are boosted. The inescapable properties of the ED and of hospitals in general, limited time and high levels of stress are not the only hurdles to reaching this objective. Furthermore, human working memory is limited in the number of items it can hold. In his landmark analysis, Miller (1956) observed that humans can recall only seven plus/minus two units ('chunks') of information. To date, few studies have investigated which factors may be associated with individual differences in the recall of health information: First, a moderate inverse correlation has been reported between age and amount of information recalled correctly (Jansen et al., 2008; Morrow, Leirer, Carver, Tanke, \& McNally, 1999); high levels of stress and anxiety hamper recall of medical information (Ley, 1979; Shapiro, Boggs, Melamed, \& Graham-Pole, 1992); and limited literacy has repeatedly been linked to problems comprehending and, by extension, recalling health information (Baker et al., 2007; DeWalt, Berkman, Sheridan, Lohr, \& Pignone, 2004; Paasche-Orlow, Parker, Gazmararian, Nielsen-Bohlman, \& Rudd, 2005; Wolf, Gazmararian, \& Baker, 2005). Moreover, there also seems to be a linear association between amount of information given and amount recalled. Unsurprisingly, the more information provided, the more is lost (Safeer \& Keenan, 2005).

\section{Information structuring}

Psychological theory and associated empirical findings suggest that information structuring can be a powerful tool in improving recall and understanding (Epstein, 1967; Hannafin, 2004; Traupmann, 1975). Meta-analyses on the use of a specific type of 
information structuring, namely, advance organizers - that is, information presented by an instructor with the goal of helping the learner organize new incoming information - suggest that structure can assist learning: Hattie (2009) estimated an overall positive effect size of .4 of structuring on learning, based on a meta-analysis of 577 studies $(N=3905)$. One likely psychological mechanism underlying the benefits of information structuring appears to be chunking; that is, the association of disparate low-level individual elements into large high-level clusters (Miller, 1956). Indeed, based on controlled laboratory experiments and theoretical considerations, the ability to form high-level clusters has been directly linked to increases in recall capacity, making it a useful tool for memorizing large amounts of information (Chen \& Cowan, 2005; Gobet et al., 2001; Li et al., 2013).

How the structure implied by prior knowledge affects memory performance has been studied extensively in research on human memory (Bartlett, 1932; Bellezza \& Bower, 1981; Bransford \& Johnson, 1972; Craik \& Tulving, 1975) and it is thought that 'prior knowledge facilitates processing of new incoming information, presumably because it provides a structure into which the new information can be integrated, which may lead to an elaborate memory trace' (Brod, Werkle-Bergner, \& Shing, 2013, p. 2). Considering the role of information structuring in discharge communication, one may therefore predict that its benefits are largest when there is no prior internal structure that can guide information encoding. The extent to which structuring the presentation of discharge information may improve patients' recall and how such benefits are moderated by the presence of relevant medical knowledge has not yet been examined.

\section{The current study}

The power of information structuring has primarily been studied in the laboratory; no previous studies have investigated its role in improving discharge information delivery. Could information structuring also improve patients' recall of discharge information? Studying these questions experimentally in the ED would be demanding and potentially stressful for patients. Therefore, we decided to use students as proxy patients. We thus adopted a similar strategy to previous studies that have used proxies, such as health care professionals or family caregivers, to evaluate certain patient outcomes, such as health-related quality of life (Pickard \& Knight, 2005), functional ability (Loewenstein et al., 2001), or symptoms (Nekolaichuk et al., 1999). Our objective was to present three different populations differing in their degree of medical knowledge with either a structured or non-structured discharge communication video. The information provided in the videos stemmed from previous work that identified the desired content of effective discharge communication in patients presenting with acute chest pain (Ackermann et al., 2015).

Assuming that externally imposed structure yields benefits in terms of memory performance, our first hypothesis is that students recall more information when it is presented in a structured way as compared to a non-structured presentation. Furthermore, assuming that structure should benefit mostly if internal structure is unavailable, our second hypothesis is that the extent to which structuring a communication benefits recall performance interacts with the degree of prior knowledge. 

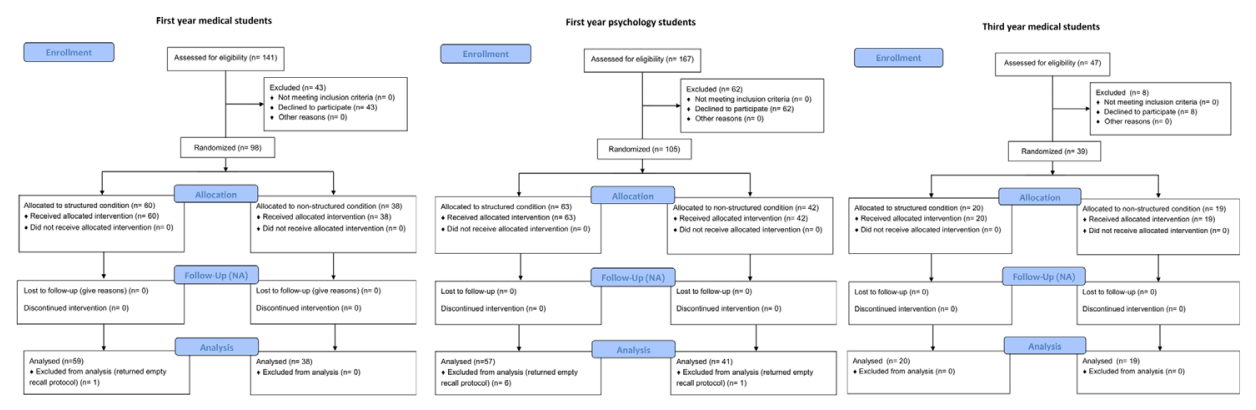

Figure 1. Flow diagrams of the randomized clinical trial, separately for each group of students.

\section{Materials and methods}

\section{Design overview}

We conducted a prospective cross-sectional randomized multicenter trial at the Universities of Basel, Switzerland, and Mannheim, Germany, using a $3 \times 2$ between-subjects experimental design, the factors being 'condition' (structured vs. non-structured) and 'group' (first year psychology students vs. first year medical students vs. third year medical students) and the dependent variable being number of items recalled. The study protocol was approved by the local ethics committees (Ethikkommission Nordwest- und Zentralschweiz; ClinicalTrials. gov ID: NCT01540266). Written informed consent was obtained from all participants.

\section{Setting and participants}

The study was conducted by three team members during regular weekly lectures in two auditoriums at the Universities of Basel and Mannheim. We recruited three independent populations: first year medical students at the University of Mannheim $(n=97)$, third year medical students at the University of Basel $(n=39)$, and first year psychology students at the University of Basel $(n=98)$. Students were deemed eligible for participation if they were older than 18 years.

\section{Randomization and interventions}

Data collection was performed on three weekdays in two different auditoriums. Flow diagrams of the randomized trial are shown in Figure 1. Students were randomly assigned to either the structured (S) or the non-structured (NS) condition at the outset of the lecture, by the letters $\mathrm{A}$ and $\mathrm{B}$ marked on the envelopes containing the study material, which had been distributed on the students' tables prior to the lecture's start (simple randomization, blinded for participating students). They received written information about the study and were told that their task was to take a patient's perspective and evaluate the communication shown in a video. After this introduction, students with A-envelopes were instructed to stay in the auditorium, whereas students with B-envelopes were instructed to go to a different auditorium. The two groups each were then shown a video in which the same physician conveyed the identical set of 28 items of information (Table 1 ) to an elderly patient (played by an actor) in either structured or non-structured form. In the non-structured (NS) condition, 
Table 1. The 28 items conveyed to an elderly patient.

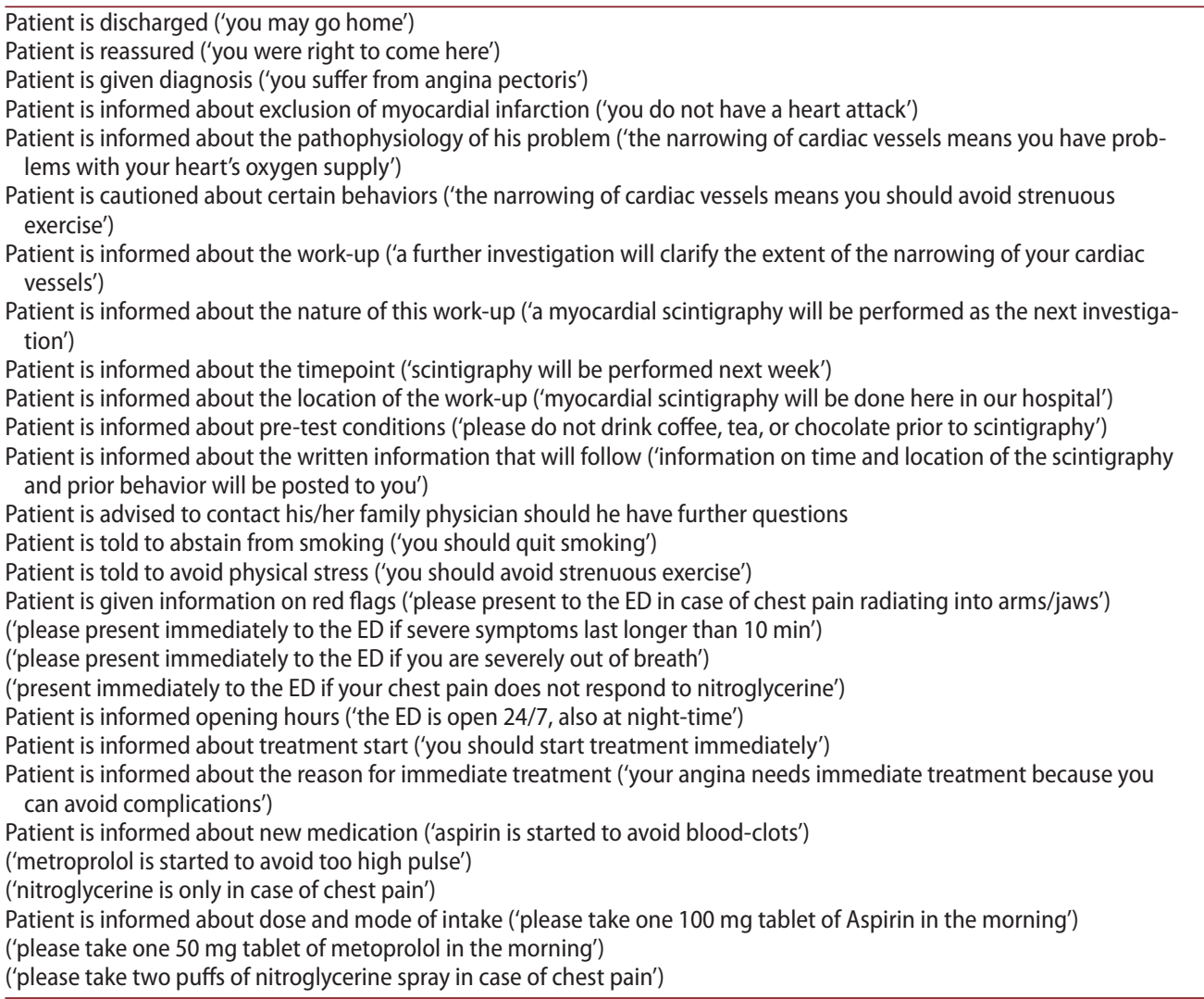

the information presented had no explicit structure. In the structured (S) condition, the information was well structured, following the structural elements of a book, in which the content is presented in a specific order, typically advancing from high-level information (e.g. title, table of contents, chapter headings) to detailed, low-level information (e.g. text, annexes; Langewitz, 2011).

After watching the video, participants were given five minutes to take down all the items of information they remembered. In addition, they were asked to rate the comprehensibility of the physician's communication, the structure of the dialogue, and their willingness to recommend the physician to friends and relatives on a Visual Analogue Scale (VAS; from 0 to 10). Participants' current mood and level of attention were also assessed using a VAS to test for moderating effects of their current status. Their medical knowledge was assessed by a multiple choice test comprising six questions (Table 2). Additionally, the following variables were recorded: gender, age, and, in order to better be able to describe the student population, nationality, number of semesters completed, faculty, and university.

\section{Outcome measures}

The key memory measure was immediate recall performance expressed as the number of items recalled. Participants' recall protocols were evaluated by two independent raters, one of whom rated all protocols and the other, only a subset. Analyses of the 
Table 2. Multiple choice questions used to assess participants' medical knowledge (correct answers in bold).

\begin{tabular}{|c|c|c|}
\hline & Question & Answers \\
\hline$\overline{\mathrm{Q} 1}$ & $\begin{array}{l}\text { A myocardial infarction } \\
\text { is }\end{array}$ & $\begin{array}{l}\text { A: a sudden irregularity of the cardiac pulse/rhythm leading to severe pain } \\
\text { B: a gradual narrowing of the heart's coronary vessels } \\
\text { C: a sudden weakness of the cardiac muscle } \\
\text { D: death of part of the cardiac muscle due to lack of oxygen }\end{array}$ \\
\hline Q2 & $\begin{array}{l}\text { Angina pectoris is } \\
\text { defined as }\end{array}$ & $\begin{array}{l}\text { A: dyspnea caused by disturbed heart rhythm } \\
\text { B: pain caused by an overstrained heart } \\
\text { C: pain caused by short-term underoxygenation of the cardiac muscle } \\
\text { D: disturbed heart rhythm caused by short-term underoxigenatin of the cardiac } \\
\text { muscle }\end{array}$ \\
\hline Q3 & $\begin{array}{l}\text { What is a risk factor } \\
\text { for cardiovascular } \\
\text { diseases? }\end{array}$ & $\begin{array}{l}\text { A: heavy work (physical labor, intensive sports) } \\
\text { B: diabetes mellitus } \\
\text { C: frequent viral infections } \\
\text { D: electromagnetic radiation (e.g. from a cell phone) }\end{array}$ \\
\hline Q4 & $\begin{array}{l}\text { Typical pain sensa- } \\
\text { tions in myocardial } \\
\text { infarction }\end{array}$ & $\begin{array}{l}\text { A: increase during inhalation } \\
\text { B: radiate into the left arm } \\
\text { C: occur with sudden limb movement } \\
\text { D: radiate from the left thorax to the right thorax }\end{array}$ \\
\hline Q5 & $\begin{array}{l}\text { A cardiac angiogra- } \\
\text { phy is }\end{array}$ & $\begin{array}{l}\text { A: an ultrasound of the coronary vessels } \\
\text { B: a computed tomography }(\mathrm{CT}) \text { of the coronary vessels } \\
\text { C: an ultrasound of the heart } \\
\text { D: a radiographic examination of the coronary vessels }\end{array}$ \\
\hline Q6 & $\begin{array}{l}\text { Typical cardiac pain } \\
\text { worsens with }\end{array}$ & $\begin{array}{l}\text { A: rapid breathing } \\
\text { B: emotional stress } \\
\text { C: physical exertion } \\
\text { D: lifting of both arms }\end{array}$ \\
\hline
\end{tabular}

agreement between the two raters resulted in a Cohen's kappa of .74, indicating substantial interrater reliability according to Landis and Koch (1977). In case of disagreement between the two raters, consensus was reached through joint analysis and discussion of the protocols.

\section{Statistical analyses}

All analyses were performed with PASW Statistics 18 (SPSS Inc., Chicago, USA). The difference in recall performance between each pair of the three groups (main effect of 'group': first year psychology students vs. first year medical students; first year psychology students vs. third year medical students; first year medical students vs. third year medical students) and between the two conditions (main effect of 'condition': structured vs. non-structured discharge information) as well as their interaction 'group $\times$ condition' was assessed by the means of a $2 \times 3$ analysis of variance (ANOVA). Effect sizes were calculated using Cohen's $d$ for both main effects and their interaction $(d=.2, .5$, and .8 represent effects of small, medium, and large size, respectively (Cohen, 1988)). Non-parametric Mann-Whitney tests were performed to probe for inter- and intragroup differences in medical knowledge of first year psychology students, first year medical students, and third year medical students. An independent samples $t$-test analysis was used to compare differences between the structured and non-structured conditions in terms of participants' VAS ratings of the comprehensibility of the physician, the dialogue structure, willingness to recommend the physician, current mood, and level of attention. Finally, in order to establish the independence of the main effects 'group' and 'condition' as well as their interaction 'group $\times$ condition' from the 
influence of current mood, and level of attention on the number of recalled items, we performed a $2 \times 3$ analysis of covariance (ANCOVA), again number of recalled items being the dependent variable and 'group' and 'condition' being the factors. All tests were performed at a significance level of $\alpha=.05$.

\section{Results}

\section{Recall}

Demographics are summarized in Table 3. The ANOVA revealed a significant main effect of 'condition', $F(1,228)=4.45 ; p=.036 ; \eta_{p}^{2}=.019$, albeit with a small effect size, $d=.28$ (effect size's 95\%-confidence interval $\left.\left(C I_{d}\right)=.021-.54\right)$ : overall, the 234 participating students recalled a mean of 9.12 (33\%) of the 28 items presented (range: $0-23$ items; Table $3)$. Students randomized to the structured condition recalled a mean of 9.70 items (35\%); those randomized to the non-structured condition recalled a mean of 8.31 items $(30 \%$; Table 3), amounting to a relative boost of recall of $17 \%$. The main effect of 'group' on recall performance proved also to be significant, $F(1,228)=27.9 ; p<.01 ; \eta_{p}^{2}=.196$. Third year medical students recalled the highest number of items $(M=13.2,47 \%$, range: $4-23)$, followed by first year medical students $(M=9.49,34 \%$, range: $0-19)$, and first year psychology students $(M=7.11,25 \%$; range: $0-19$; Table 3). Each comparison between pairs of groups was statistically significant (first year psychology students vs. first year medical students: $p<.01 ; d=.52 ; 95 \%-C I_{d}=.23-.81 ;$ first year psychology students vs. third year medical students: $p<.01 ; d=1.43 ; 95 \%-C I_{d}=1.01-1.83$; first year medical students vs. third year medical students: $\left.p<.01 ; d=.80 ; 95 \%-C I_{d}=.41-1.17\right)$.

Next, we considered the potential benefit of structure as a function of medical knowledge (Figure 2). Although the interaction of 'condition $\times$ group' proved to be statistically non-significant $\left(F(2,228)=.80 ; p=.45 ; \eta_{p}^{2}=.007\right)$, the magnitude of the effects of information structuring varies systematically by the degree of medical knowledge: although only a negligible benefit of structured information could be observed in third year medical students $\left(M_{S}=13.5\right.$ vs. $\left.M_{N S}=13.0 ; d=.12 ; 95 \%-C I_{d}=-.52-.74\right)$, we found a small effect size of information structuring in first year medical students $\left(M_{S}=9.95\right.$ vs. $M_{N S}=8.76$; $\left.d=.24 ; 95 \%-C I_{d}=-.17-.65\right)$, and a medium effect size in first year psychology students $\left(M_{S}=8.12\right.$ vs. $\left.M_{N S}=5.71 ; d=.60 ; 95 \%-C I_{d}=.18-1.00\right)$, amounting to a relative increase of recall performance by $42 \%$.

\section{Medical knowledge}

A Mann-Whitney $U$-test of differences in participants' medical knowledge confirmed that the three groups had different degrees of medical knowledge: first year psychology students' performance in each of the six multiple choice questions was significantly worse than that of third year medical students or first year medical students (Table 4). Comparison of the percentage of correct answers provided by the two groups of medical students (Table 3) shows that third year medical students performed better in four of the six questions and equally well in the remaining two. However, the U-test analyses showed a significant difference between these two groups only in one question (Q3; see Table 4). 


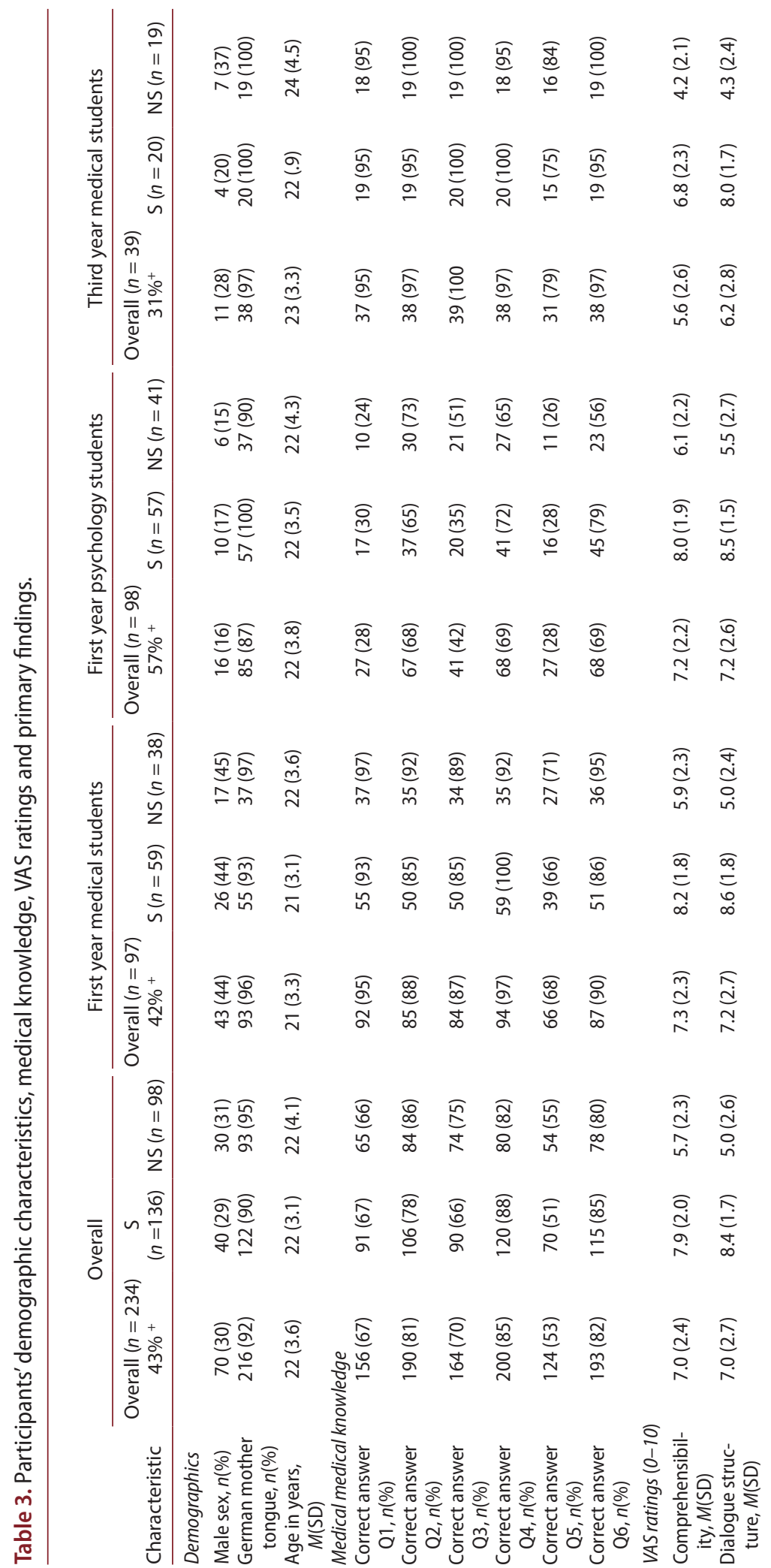




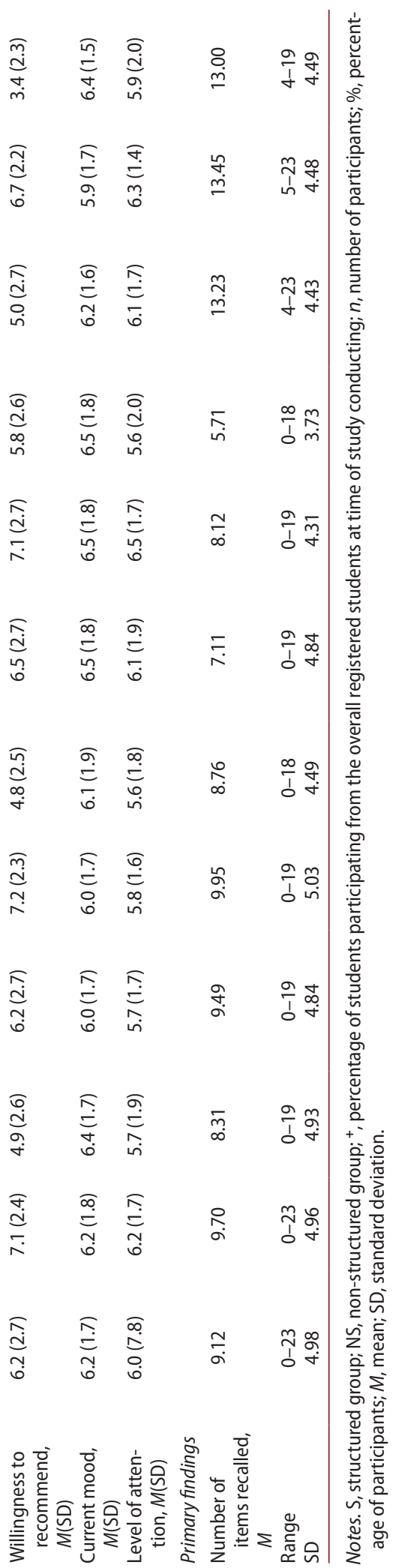




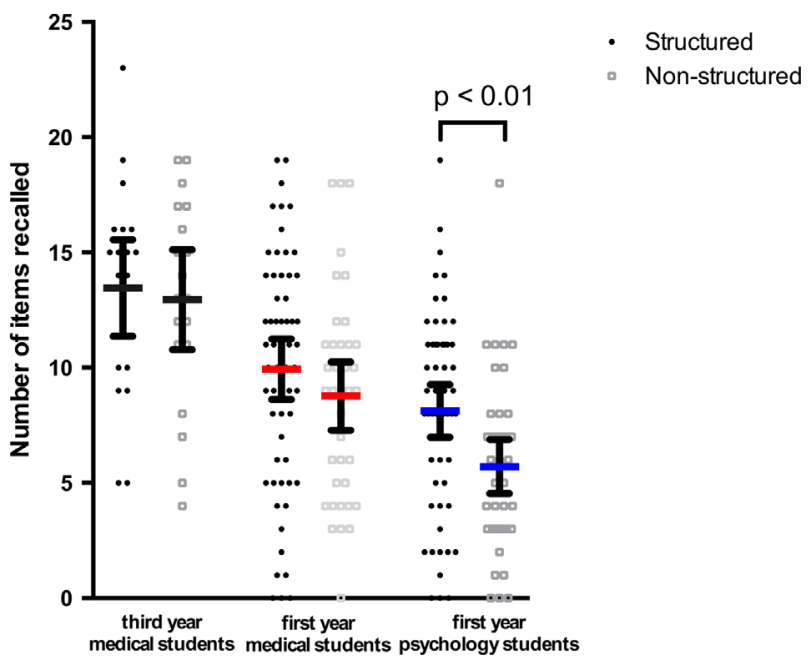

Figure 2. Number of items recalled by participants in the structured and non-structured conditions, separately for each group.

Table 4. Results from Mann-Whitney U-tests of differences in participants' medical knowledge.

\begin{tabular}{|c|c|c|c|c|c|c|}
\hline & \multicolumn{2}{|c|}{$\begin{array}{l}\text { First year medical students vs. } \\
\text { first year psychology students }\end{array}$} & \multicolumn{2}{|c|}{$\begin{array}{c}\text { First year medical students } \\
\text { vs. third year medical } \\
\text { students }\end{array}$} & \multicolumn{2}{|c|}{$\begin{array}{l}\text { First year psychology stu- } \\
\text { dents vs. third year medical } \\
\text { students }\end{array}$} \\
\hline & $U$ & $p$ & $U$ & $p$ & $U$ & $p$ \\
\hline$\overline{\mathrm{Q} 1}$ & 1552 & $<.01^{*}$ & 1891 & .99 & 623 & $<.01^{*}$ \\
\hline Q2 & 3722 & $<.01^{*}$ & 1705 & .10 & 1352 & $<.01^{*}$ \\
\hline Q3 & 2619 & $<.01^{*}$ & 1638 & $.02^{*}$ & 799 & $<.01^{*}$ \\
\hline Q4 & 3443 & $<.01^{*}$ & 1881 & .87 & 1374 & $<.01^{*}$ \\
\hline Q5 & 2673 & $<.01^{*}$ & 1675 & .18 & 878 & $<.01^{*}$ \\
\hline Q6 & 3691 & $<.01^{*}$ & 1744 & .17 & 1373 & $<.01^{*}$ \\
\hline
\end{tabular}

Note. U, Mann-Whitney $U ; p, p$-value.

*indicate statistically significant differences between the two groups tested.

\section{Subjective measures and additional covariates}

Independent samples $t$-test analyses of participants' subjective ratings showed that participants in the structured condition rated the quality of communication significantly higher than did participants in the non-structured condition on all three attributes tested (overall as well as across the three subgroups; Table 5 and Figure 3). No differences were observed in the ratings of current mood (Table 5). Among first year psychology students, reported attention levels were significantly lower in the NS condition than in the S condition. No corresponding differences between the conditions were observed for first year medical students or third year medical students (Table 5).

The ANCOVA revealed the following (Table 6): The main effect of group on the number of recalled items remained statistically significant with control for either covariate (current mood, attention level). The main effect of condition on the number of recalled items remained statistically significant with control for current mood and marginally statistically significant with control for level of attention. The interaction 'condition $\times$ group' remained statistically non-significant with control for either covariate. Thus, the main effects 
Table 5. Results from $t$-tests of differences in VAS ratings.

\begin{tabular}{|c|c|c|c|c|c|c|c|}
\hline & & & $\begin{array}{l}\text { Compre- } \\
\text { hensibility }\end{array}$ & $\begin{array}{l}\text { Dialogue } \\
\text { structure }\end{array}$ & $\begin{array}{l}\text { Willingness } \\
\text { to recom- } \\
\text { mend }\end{array}$ & $\begin{array}{c}\text { Current } \\
\text { mood }\end{array}$ & $\begin{array}{l}\text { Level of } \\
\text { attention }\end{array}$ \\
\hline \multicolumn{8}{|l|}{ Overall } \\
\hline & $S$ & $m$ & 7.94 & 8.45 & 7.07 & 6.17 & 6.19 \\
\hline & & SD & 1.97 & 1.67 & 2.44 & 1.75 & 1.66 \\
\hline & & SE & .17 & .14 & .21 & .15 & .14 \\
\hline & NS & $m$ & 5.68 & 5.04 & 4.92 & 6.35 & 5.69 \\
\hline & & SD & 2.34 & 2.65 & 2.63 & 1.74 & 1.94 \\
\hline & & $\mathrm{SE}$ & .24 & .26 & .27 & .18 & .20 \\
\hline & & $t$ & 7.76 & 11.50 & 6.43 & -.78 & 1.12 \\
\hline & & $\mathrm{d} f$ & 186 & 155 & 232 & 232 & 232 \\
\hline & & $\mathrm{Cl}$ & $1.67-2.84$ & $2.81-3.99$ & $1.49-2.80$ & $-.63-.27$ & $.04-.97$ \\
\hline & & $p$ & $<.01^{*}$ & $<.01^{*}$ & $<.01^{*}$ & .44 & $.04^{*}$ \\
\hline \multicolumn{8}{|c|}{$\begin{array}{l}\text { First year } \\
\text { medical } \\
\text { students }\end{array}$} \\
\hline & $\mathrm{S}$ & $m$ & 8.21 & 8.56 & 7.20 & 5.95 & 5.83 \\
\hline & & SD & 1.84 & 1.77 & 2.34 & 1.69 & 1.62 \\
\hline & & SE & .24 & .23 & .30 & .22 & .21 \\
\hline & NS & $m$ & 5.93 & 4.99 & 4.76 & 6.14 & 5.60 \\
\hline & & SD & 2.33 & 2.44 & 2.53 & 1.85 & 1.76 \\
\hline & & SE & .38 & .40 & .41 & .30 & .29 \\
\hline & & $t$ & 5.36 & 7.82 & 4.86 & -.51 & .65 \\
\hline & & $\mathrm{d} f$ & 95 & 62 & 95 & 95 & 95 \\
\hline & & $\mathrm{Cl}$ & $1.43-3.12$ & $2.66-4.49$ & $1.44-3.43$ & $-.91-.54$ & $-.46-.92$ \\
\hline & & $p$ & $<.01^{*}$ & $<.01^{*}$ & $<.01^{*}$ & .61 & .52 \\
\hline \multicolumn{8}{|c|}{$\begin{array}{l}\text { First year } \\
\text { psychology } \\
\text { students }\end{array}$} \\
\hline & $\mathrm{S}$ & $m$ & 8.05 & 8.48 & 7.08 & 6.50 & 6.52 \\
\hline & & SD & 1.89 & 1.55 & 2.66 & 1.81 & 1.74 \\
\hline & & SE & .25 & .20 & .35 & .24 & .23 \\
\hline & NS & $m$ & 6.12 & 5.45 & 5.78 & 6.51 & 5.65 \\
\hline & & SD & 2.24 & 2.74 & 2.56 & 1.77 & 2.07 \\
\hline & & SE & .35 & .43 & .40 & .23 & .32 \\
\hline & & $t$ & 4.59 & 6.38 & 2.43 & -.04 & 2.24 \\
\hline & & $\mathrm{d} f$ & 96 & 58 & 96 & 96 & 96 \\
\hline & & $\mathrm{Cl}$ & $1.09-2.76$ & $2.08-3.98$ & $.24-2.37$ & $-.74-.72$ & $.10-1.63$ \\
\hline & & $p$ & $<.01^{*}$ & $<.01^{*}$ & $.02^{*}$ & .97 & $.03^{*}$ \\
\hline \multicolumn{8}{|c|}{$\begin{array}{c}\text { Third year } \\
\text { medical } \\
\text { students }\end{array}$} \\
\hline & $\mathrm{S}$ & $m$ & 6.84 & 8.02 & 6.63 & 5.89 & 6.30 \\
\hline & & SD & 2.29 & 1.70 & 2.16 & 1.70 & 1.34 \\
\hline & & SE & .51 & .38 & .48 & .38 & .31 \\
\hline & NS & $m$ & 4.21 & 4.29 & 3.38 & 6.43 & 5.94 \\
\hline & & SD & 2.13 & 2.36 & 2.29 & 1.46 & 2.05 \\
\hline & & SE & .49 & .54 & .53 & .33 & .47 \\
\hline & & $t$ & 3.70 & 5.70 & 4.61 & -1.07 & .66 \\
\hline & & $\mathrm{d} f$ & 37 & 37 & 37 & 37 & 37 \\
\hline & & $\mathrm{Cl}$ & $1.19-4.06$ & $2.41-5.10$ & $1.81-4.70$ & $-1.57-0-48$ & $-.76-1.50$ \\
\hline & & $p$ & $<.01^{*}$ & $<.01^{*}$ & $<.01^{*}$ & .30 & .51 \\
\hline
\end{tabular}

Notes. S, structured group; NS, non-structured group; $m$, mean value on VAS; SD, standard deviation; SE, standard error; $t$, $t$-value; $\mathrm{d} f$, degrees of freedom; $\mathrm{Cl}, 95 \%$ confidence interval; $p, p$-value.

*indicate statistically significant differences between the two groups tested. 
Structured condition

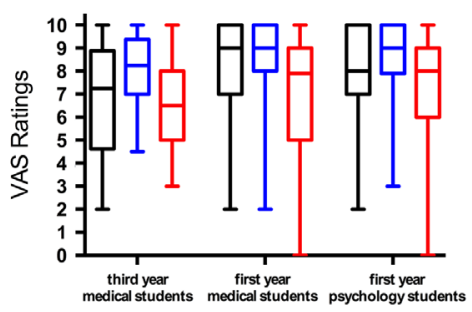

Non-structured condition

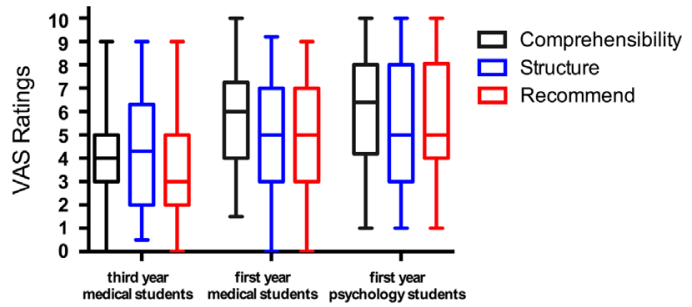

Figure 3. Participants' ratings of the comprehensibility of the physician, the structure of the dialogue, and willingness to recommend the physician to friends and relatives as a function of whether they viewed the structured or the non-structured video.

Table 6. Results from the ANCOVA with main effects of condition and of group and their interaction condition $\times$ group; and current mood and attention level as covariates.

\begin{tabular}{llccc}
\hline & & Main effect condition & Main effect group & Interaction group $\times$ condition \\
\hline Current mood & $F$ & 4.51 & 27.8 & .77 \\
& $\mathrm{~d} f$ & 1,227 & 2,227 & 2,227 \\
& $p$ & $.035^{*}$ & $<.01^{*}$ & .46 \\
Level of attention & $\eta_{p}{ }^{2}$ & .019 & .20 & .007 \\
& $F$ & 3.25 & 28.6 & .59 \\
& $\mathrm{~d} f$ & 1,227 & 2,227 & 2,227 \\
& $p$ & .073 & $<.01^{*}$ & .55 \\
& $\eta_{p}{ }^{2}$ & .014 & .20 & .005 \\
\hline
\end{tabular}

Note. $F, F$-value; $\mathrm{d} f$, degrees of freedom; $p, p$-value; $\eta_{p}{ }^{2}$, partial eta squared.

${ }^{*}$ indicate statistically significant differences between the two conditions tested.

'condition' and 'group' as well as their interaction 'condition $\times$ group' proved to be independent from the two covariates.

\section{Discussion}

Our study suggests that information structuring can improve recall. Furthermore, we find a trend such that medical knowledge was associated with recall performance: the group with the lowest levels of medical knowledge had the strongest benefits from information structuring on information recall. Third, the presentation of structured information also resulted in higher ratings in terms of perceived structure, comprehensibility, and willingness to recommend the physician to others.

These results suggest that persons with little medical knowledge may benefit substantially from structured discharge information. In contrast, structure appears to have no or little benefit on recall in persons with higher medical knowledge, such as advanced medical students. It could be argued that existing structure in a person's medical knowledge enables the receiver of information to store it more efficiently (Brod et al., 2013), even when its presentation lacks a clear structure.

With respect to the generalization of our findings, two points may warrant attention: First, among our three groups, the group of first year psychology students is likely to be most similar to patients' scope of medical knowledge. Yet, our results are more likely to underestimate the benefit of structuring information, as the recall in patients is most likely lower than in university students in general. It was shown that the amount of knowledge 
about medicine is positively correlated with level of education (Akici et al., 2004; Tang et al., 2003). Therefore, we assume that, relative to university students, patients are likely to have lower average levels of medical knowledge. In addition, the specific encoding circumstances (that is, a time of distress and possible confusion) may further impair patients' ability to recall information, as is implied by studies of the detrimental impact of stress on eyewitness memory (Deffenbacher, Bornstein, Penrod, \& McGorty, 2004). At the same time, patients with chronic conditions may have more pertinent medical knowledge than healthy university students. They may therefore better be able to integrate even unstructured information into existing knowledge structures and categories.

The relationship between structure and subsequent recall performance has previously been studied albeit in very different circumstances (Epstein, 1967; Hannafin, 2004; Traupmann, 1975). Yet, our results converge with these previous findings: structure boosts recall in particular when no pertinent medical knowledge is accessible. This boost in recall would be even more noteworthy if future research found that better recall performance is not randomly distributed across all communicated items but in particular benefits items of highest significance (e.g. information on 'red flags', giving clear advice, when and why to seek immediate medical attention under given circumstances).

One limitation of our study concerns the presentation of information: To be able to standardize the presentations, we used video clips rather than real-life interactions. Reallife communication offers many opportunities to tailor information and speed of delivery to recipients' reactions: Subtle cues can indicate the need to slow down the presentation or to speed up because the recipient is more knowledgeable than the sender assumes. The staged interaction's representativeness of a real situation in the ED, where stress and time pressure are two ubiquitous factors, and therefore the generalizability of our results may thus be questioned. Furthermore, one may argue that a sample of psychology students is not representative of the average patient newly diagnosed with coronary heart disease. This is hard to dispute. However, even in this highly constrained situation, we observed that participants' recall performance was far from perfect. In fact, even the best group recalled less than half of the information conveyed. Thus, even young, well-educated students, experts in submitting information to memory, were overtaxed. This coincidental but important finding, strongly suggests that the amount of information presented in clinical interactions has to be considered more carefully (Ackermann et al., 2015).

Future research evaluating the benefits of structure in the presentation of discharge information will need to focus on actual interactions between patients presenting to the ED and emergency physicians. Taken together, this study represents a step on the long road towards effective and safe discharge communication.

\section{Acknowledgements}

The authors thank Eugen Disch, Sabine Vollstädt-Klein, Nicole Dies, Pasquale Calabrese, Alexander Grob, Klaus Bally and Ladina Joos for the opportunity to conduct the experiments during their lectures, and Laura Wiles and Susannah Goss for critically editing the manuscript.

\section{Disclosure statement}

No potential conflict of interest was reported by the authors. 


\section{Funding}

The study was funded by the Scientific Fund of the Department of Emergency Medicine, University Hospital Basel, Switzerland.

\section{References}

Ackermann, S., Heierle, A., Bingisser, M. B., Hertwig, R., Padiyath, R., Nickel, C. H., ... Bingisser, R. (2015). Discharge communication in patients presenting to the emergency department with chest pain: Defining the ideal content. Health Commun, 31, 1-9. doi:http://dx.doi.org/10.1080/1 0410236.2014.979115

Akici, A., Kalaça, S., Uğurlu, M. U., Toklu, H. Z., Iskender, E., \& Oktay, S. (2004). Patient knowledge about drugs prescribed at primary healthcare facilities. Pharmacoepidemiology and Drug Safety, 13, 871-876. doi:http://dx.doi.org/10.1002/pds.1020

Baker, D. W., Wolf, M. S., Feinglass, J., Thompson, J. A., Gazmararian, J. A., \& Huang, J. (2007). Health literacy and mortality among elderly persons. Archives of Internal Medicine, 167, 1503-1509. doi:http://dx.doi.org/10.1001/archinte.167.14.1503

Bartlett, F. C. (1932). Remembering: A study in experimental and social psychology. Cambridge: Cambridge University Press.

Bazarian, J., Hartman, M., \& Delahunta, E. (2000). Minor head injury: Predicting follow-up after discharge from the Emergency Department. Brain Injury, 14, 285-294.

Bellezza, F. S., \& Bower, G. H. (1981). The representational and processing characteristics of scripts. Bulletin of the Psychonomic Society, 18, 1-4. doi:http://dx.doi.org/10.3758/BF03333553

Bransford, J. D., \& Johnson, M. K. (1972). Contextual prerequisites for understanding: Some investigations of comprehension and recall. Journal of Verbal Learning and Verbal Behavior, 11, 717-726. doi:http://dx.doi.org/10.1016/S0022-5371(72)80006-9

Brod, G., Werkle-Bergner, M., \& Shing, Y. L. (2013). The influence of prior knowledge on memory: A developmental cognitive neuroscience perspective. Frontiers in Behavioral Neuroscience, 7, 1-13. doi:http://dx.doi.org/10.3389/fnbeh.2013.00139

Butler, K., \& Cooper, W. O. (2004). Adherence of pediatric asthma patients with oral corticosteroid prescriptions following pediatric emergency department visit or hospitalization. Pediatric Emergency Care, 20, 730-735.

Chen, Z., \& Cowan, N. (2005). Chunk limits and length limits in immediate recall: A reconciliation. Journal of Experimental Psychology: Learning, Memory, and Cognition, 31, 1235-1249. doi:http:// dx.doi.org/10.1037/0278-7393.31.6.1235

Clarke, C., Friedman, S. M., Shi, K., Arenovich, T., Monzon, J., \& Culligan, C. (2005). Emergency department discharge instructions comprehension and compliance study. Canadian Journal of Emergency Medicine, 7, 5-11.

Cohen, J. (1988). Statistical power analysis for the behavioral sciences (2nd ed.). Hillsdale, NJ: Lawrence Erlbaum.

Considine, J., \& Brennan, D. (2007). Effect of an evidence-based education programme on ED discharge advice for febrile children. Journal of Clinical Nursing, 16, 1687-1694. doi:http://dx.doi. org/10.1111/j.1365-2702.2006.01716.x

Craik, F. I. M., \& Tulving, E. (1975). Depth of processing and the retention of words in episodic memory. Journal of Experimental Psychology: General, 104, 268-294. doi:http://dx.doi.org/10.1037/00963445.104.3.268

Crane, J. A. (1997). Patient comprehension of doctor-patient communication on discharge from the emergency department. The Journal of Emergency Medicine, 15, 1-7. doi:S0736467996002612 [pii]

Deffenbacher, K. A., Bornstein, B. H., Penrod, S. D., \& McGorty, E. K. (2004). A meta-analytic review of the effects of high stress on eyewitness memory. Law and Human Behavior, 28, 687-706.

DeWalt, D. A., Berkman, N. D., Sheridan, S., Lohr, K. N., \& Pignone, M. P. (2004). Literacy and health outcomes: A systematic review of the literature. Journal of General Internal Medicine, 19, 1228-1239. doi:http://dx.doi.org/10.1111/j.1525-1497.2004.40153.x 
Engel, K. G., Buckley, B. A., Forth, V. E., McCarthy, D. M., Ellison, E. P., Schmidt, M. J., \& Adams, J. G. (2012). Patient understanding of emergency department discharge instructions: Where are knowledge deficits greatest? Academic Emergency Medicine, 19, E1035-E1044. doi:http://dx.doi. org/10.1111/j.1553-2712.2012.01425.x

Engel, K. G., Heisler, M., Smith, D. M., Robinson, C. H., Forman, J. H., \& Ubel, P. A. (2009). Patient comprehension of emergency department care and instructions: Are patients aware of when they do not understand? Annals of Emergency Medicine, 53, 454-461. e415. doi:http://dx.doi.org/10.1016/j. annemergmed.2008.05.016

Epstein, W. (1967). Some conditions of the influence of syntactical structure on learning: Grammatical transformation, learning instructions, and 'chunking. Journal of Verbal Learning and Verbal Behavior, 6, 415-419.

Fink, A. S., Prochazka, A. V., Henderson, W. G., Bartenfeld, D., Nyirenda, C., Webb, A., \& Parmelee, P. (2010). Enhancement of surgical informed consent by addition of repeat back: A multicenter, randomized controlled clinical trial. Annals of Surgery, 252, 27-36. doi:http://dx.doi.org/10.1097/ SLA.0b013e3181e3ec61

Foran, A., Wuerth-Sarvis, B., \& Milne, W. K. (2010). Bounce-back visits in a rural emergency department. The Canadian Journal of Rural Medicine, 15, 108-112.

Gobet, F., Lane, P. C., Croker, S., Cheng, P. C., Jones, G., Oliver, I., \& Pine, J. M. (2001). Chunking mechanisms in human learning. Trends in Cognitive Sciences, 5, 236-243. doi:S1364-6613(00)01662-4 [pii]

Graumlich, J. F., Novotny, N. L., Nace, G. S., \& Aldag, J. C. (2009). Patient and physician perceptions after software-assisted hospital discharge: Cluster randomized trial. Journal of Hospital Medicine, 4, 356-363. doi:http://dx.doi.org/10.1002/jhm.565

Grover, G., Berkowitz, C. D., \& Lewis, R. J. (1994). Parental recall after a visit to the emergency department. Clinical Pediatrics, 33, 194-201.

Hahn-Goldberg, S., Okrainec, K., Damba, C., Huynh, T., Lau, D., Maxwell, J., ... Abrams, H. B. (2016). Implementing patient-oriented discharge summaries (PODS): A multisite pilot across early adopter hospitals. Healthcare Quarterly, 19, 42-48.

Han, C. Y., Barnard, A., \& Chapman, H. (2009). Discharge planning in the emergency department: A comprehensive approach. Journal of Emergency Nursing, 35, 525-527. doi:http://dx.doi. org/10.1016/j.jen.2009.01.015

Hannafin, R. D. (2004). Achievement differences in structured versus unstructured instructional geometry programs. Educational Technology Research and Development, 52, 19-32.

Hastings, S. N., Barrett, A., Weinberger, M., Oddone, E. Z., Ragsdale, L., Hocker, M., \& Schmader, K. E. (2011). Older patients' understanding of emergency department discharge information and its relationship with adverse outcomes. Journal of Patient Safety, 7, 19-25. doi:http://dx.doi. org/10.1097/PTS.0b013e31820c7678 01209203-201103000-00004 [pii]

Hattie, J. A. (2009). Visible learning: A synthesis of over 800 meta analyses relating to achievement. New York, NY: Routledge.

Houts, P. S., Bachrach, R., Witmer, J. T., Tringali, C. A., Bucher, J. A., \& Localio, R. A. (1998). Using pictographs to enhance recall of spoken medical instructions. Patient Education and Counseling, $35,83-88$.

Isaacman, D. J., Purvis, K., Gyuro, J., Anderson, Y., \& Smith, D. (1992). Standardized instructions: Do they improve communication of discharge information from the emergency department? Pediatrics, 89, 1204-1208.

Jansen, J., Butow, P. N., van Weert, J. C., van Dulmen, S., Devine, R. J., Heeren, T. J., ... Tattersall, M. H. (2008). Does age really matter? Recall of information presented to newly referred patients with cancer. Journal of Clinical Oncology, 26, 5450-5457. doi:http://dx.doi.org/10.1200/JCO.2007.15.2322

Johnson, A., \& Sandford, J. (2005). Written and verbal information versus verbal information only for patients being discharged from acute hospital settings to home: Systematic review. Health Education Research, 20, 423-429. doi:http://dx.doi.org/10.1093/her/cyg141

Jolly, B. T., Scott, J. L., \& Sanford, S. M. (1995). Simplification of emergency department discharge instructions improves patient comprehension. Annals of Emergency Medicine, 26, 443-446. 
Knopp, R., Rosenzweig, S., Bernstein, E., \& Totten, V. (1996). Physician-patient communication in the emergency department, Part 1. Academic Emergency Medicine, 3, 1065-1069.

Landis, J. R., \& Koch, G. G. (1977). The measurement of observer agreement for categorical data. Biometrics, 33, 159-174.

Langewitz, W. (2011). Patient-centered communication. In R. A. Adler, W. Herzog, P. Joraschky, K. Köhle, W. Langewitz, W. Söllner, \& W. Wesiack (Eds.), Psychosomatische Medizin: Theoretische Modelle und klinische Praxis (pp. 338-347). München: Elsevier, Urban \& Fischer.

Lerman, B., \& Kobernick, M. S. (1987). Return visits to the emergency department. The Journal of Emergency Medicine, 5, 359-362.

Ley, P. (1979). Memory for medical information. British Journal of Social and Clinical Psychology, $18,245-255$.

Li, G., Ning, N., Ramanathan, K., He, W., Pan, L., \& Shi, L. (2013). Behind the magical numbers: Hierarchical chunking and the human working memory capacity. International Journal of Neural Systems, 23, 1350019. doi:http://dx.doi.org/10.1142/S0129065713500196

Loewenstein, D. A., Arguelles, S., Bravo, M., Freeman, R. Q., Arguelles, T., Acevedo, A., \& Eisdorfer, C. (2001). Caregivers' judgments of the functional abilities of the alzheimer's disease patient: A comparison of proxy reports and objective measures. The Journals of Gerontology Series B: Psychological Sciences and Social Sciences, 56, P78-84.

Logan, P. D., Schwab, R. A., Salomone, J. A., 3rd, \& Watson, W. A. (1996). Patient understanding of emergency department discharge instructions. Southern Medical Journal, 89, 770-774.

Miller, G. A. (1956). The magical number 7, plus or minus 2 - Some limits on our capacity for processing information. Psychological Review, 63, 81-97.

Morrow, D. G., Leirer, V. O., Carver, L. M., Tanke, E. D., \& McNally, A. D. (1999). Effects of aging, message repetition, and note-taking on memory for health information. The Journals of Gerontology Series B: Psychological Sciences and Social Sciences, 54, P369-379.

Nekolaichuk, C. L., Bruera, E., Spachynski, K., MacEachern, T., Hanson, J., \& Maguire, T. O. (1999). A comparison of patient and proxy symptom assessments in advanced cancer patients. Palliative Medicine, 13, 311-323.

Ong, L. M., de Haes, J. C., Hoos, A. M., \& Lammes, F. B. (1995). Doctor-patient communication: A review of the literature. Social Science \& Medicine, 40, 903-918.

Paasche-Orlow, M. K., Parker, R. M., Gazmararian, J. A., Nielsen-Bohlman, L. T., \& Rudd, R. R. (2005). The prevalence of limited health literacy. Journal of General Internal Medicine, 20, 175-184. doi:http://dx.doi.org/10.1111/j.1525-1497.2005.40245.x

Pickard, A. S., \& Knight, S. J. (2005). Proxy evaluation of health-related quality of life: A conceptual framework for understanding multiple proxy perspectives. Medical Care, 43, 493-499.

Racine, A. D., Alderman, E. M., \& Avner, J. R. (2009). Effect of telephone calls from primary care practices on follow-up visits after pediatric emergency department visits: Evidence from the Pediatric Emergency Department Links to Primary Care (PEDLPC) randomized controlled trial. Archives of Pediatrics \& Adolescent Medicine, 163, 505-511. doi:http://dx.doi.org/10.1001/ archpediatrics.2009.45

Rogers, A. M., Ramanath, V. S., Grzybowski, M., Riba, A. L., Jani, S. M., Mehta, R., ... American College of Cardiology Foundation Bethesda, MD. (2007). The association between guideline-based treatment instructions at the point of discharge and lower 1-year mortality in medicare patients after acute myocardial infarction: The American College of Cardiology's Guidelines Applied in Practice (GAP) initiative in Michigan. American Heart Journal, 154, 461-469. doi:http://dx.doi. org/10.1016/j.ahj.2007.05.003

Safeer, R. S., \& Keenan, J. (2005). Health literacy: The gap between physicians and patients. American Family Physician, 72, 463-468.

Samuels-Kalow, M. E., Stack, A. M., \& Porter, S. C. (2012). Effective discharge communication in the emergency department. Annals of Emergency Medicine, 60, 152-159. doi:http://dx.doi. org/10.1016/j.annemergmed.2011.10.023

Schillinger, D., Piette, J., Grumbach, K., Wang, F., Wilson, C., Daher, C., ... Bindman, A. B. (2003). Closing the loop: Physician communication with diabetic patients who have low health literacy. Archives of Internal Medicine, 163, 83-90. 
Shapiro, D. E., Boggs, S. R., Melamed, B. G., \& Graham-Pole, J. (1992). The effect of varied physician affect on recall, anxiety, and perceptions in women at risk for breast cancer: An analogue study. Health Psychology, 11, 61-66.

Spandorfer, J. M., Karras, D. J., Hughes, L. A., \& Caputo, C. (1995). Comprehension of discharge instructions by patients in an urban emergency department. Annals of Emergency Medicine, 25, 71-74. doi:S0196-0644(95)70358-6 [pii]

Tang, E. O., Lai, C. S., Lee, K. K., Wong, R. S., Cheng, G., \& Chan, T. Y. (2003). Relationship between patients' warfarin knowledge and anticoagulation control. The Annals of Pharmacotherapy, 37, 34-39.

Traupmann, K. L. (1975). Effects of categorization and imagery on recognition and recall by process and reactive schizophrenics. Journal of Abnormal Psychology, 84, 307-314.

Vinson, D. R., \& Patel, P. B. (2009). Facilitating follow-up after emergency care using an appointment assignment system. Journal For Healthcare Quality, 31, 18-24.

Watson, P. W., \& McKinstry, B. (2009). A systematic review of interventions to improve recall of medical advice in healthcare consultations. Journal of the Royal Society of Medicine, 102, 235-243. doi:http://dx.doi.org/10.1258/jrsm.2009.090013

White, C. S., Mason, A. C., Feehan, M., \& Templeton, P. A. (1995). Informed consent for percutaneous lung biopsy: Comparison of two consent protocols based on patient recall after the procedure. American Journal of Roentgenology, 165, 1139-1142. doi:http://dx.doi.org/10.2214/ajr.165.5.7572491

Wolf, M. S., Davis, T. C., Curtis, L. M., Webb, J. A., Bailey, S. C., Shrank, W. H., ... Wood, A. J. (2011). Effect of standardized, patient-centered label instructions to improve comprehension of prescription drug use. Medical Care, 49, 96-100. doi:http://dx.doi.org/10.1097/MLR.0b013e3181f38174

Wolf, M. S., Gazmararian, J. A., \& Baker, D. W. (2005). Health literacy and functional health status among older adults. Archives of Internal Medicine, 165, 1946-1952. doi:http://dx.doi.org/10.1001/ archinte.165.17.1946

Zeng-Treitler, Q., Kim, H., \& Hunter, M. (2008). Improving patient comprehension and recall of discharge instructions by supplementing free texts with pictographs. AMIA Annual Symposium Proceedings, 6, 849-853.

Zorc, J. J., Chew, A., Allen, J. L., \& Shaw, K. (2009). Beliefs and barriers to follow-up after an emergency department asthma visit: A randomized trial. Pediatrics, 124, 1135-1142. doi:http://dx.doi. org/10.1542/peds.2008-3352 